therapy for several years. ${ }^{4} 16 \mathrm{~J}$. H. Burchenal, ${ }^{17}$ from a worldwide survey of long-term survivors in acute leukaemia, found that $50 \%$ of those who had survived five years went on to survive 15 years, generally being off all chemotherapy for the latter part of this time, none relapsing after eight years of continuous remission. If this finding can be applied to more recent series, in which 40 to $50 \%$ of patients are expected to reach five years without recurrence, then 20 to $25 \%$ should reach 15 years, which would surely indicate cure.

1 British Medical fournal, 1965, 1, 1328.

2 Tivey, H., Annals of the New York Academy of Sciences, 1954, 60, 322.

3 Lancet, 1972, 2, 910.

4 Holland, J. F., and Glidewell, O., Cancer, 1972, 30, 1480.

s Sinks, L. F., Archives of Disease in Childhood, 1972, 47, 811.

M.R.C. Leukaemia Committee and Working Party on Leukaemia in Childhood, British Medical fournal, 1973, 2, 381.

7 Campbell, A.C., et al., British Medical fournal, 1973, 2, 385.

${ }^{8}$ Till, M. M., Hardisty, R. M., and Pike, M. C., Lancet, 1973, 1, 534.

'Simone, J. V., Holland, E., and Johnson, W., Blood, 1972, 39, 759.

10 Borella, L., Green, A., and Webster, R. G., Blood, 1972, 40, 42.

11 Henderson, E. S., Annals of Internal Medicine, 1968, 69, 628.

12 Zuelzer, W. W., Blood, 1964, 24, 477.

13 Hardisty, R. M., and Till, M. M., Archives of Disease in Childhood, 1968, 43, 107.

14 Acute Leukaemia Group B., Blood, 1963, 21, 699.

15 Acute Leukaemia Group B., Blood, 1963, 21, 699.

16 Pinkel, D., Fournal of the American Medical Association, 1971, 216, 648.

17 Burchenai, J. H., Cancer, 1968, 21, 595.

\section{Disinfecting Ventilators}

For some years there has been concern over the danger of cross-infection from anaesthetic equipment and mechanical ventilators, and there is evidence that this is a real problem, though not an easy one to quantitate. ${ }^{1}$ Apart from the obvious risk that the inside of the machine and the circuit to the patient may become contaminated and so infect subsequent patients, the expired air may carry micro-organisms into the room. The outside of the ventilator may also become a source of infection, as may any other piece of operating-room furniture.

The risk from external contamination of the apparatus is the easiest to deal with, as domestic cleaning or wiping with a liquid disinfectant should probably suffice. The circuit to the patient outside the machine itself may be treated by autoclaving, low-temperature steam, pasteurization, ethylene oxide, formaldehyde vapour, or chemical antimicrobials either as liquids or aerosols. The machine itself presents difficulties. With the exception of autoclaving all the methods just listed have been used. None are convenient, some are not very effective, and some may be dangerous if not carefully controlled. The various options have been reviewed by M. K. Sykes, ${ }^{2}$ who considers that the ideal solution is the use of detachable circuits (either heat-treatable or disposable) independent of the machine itself, which will thus not need internal decontamination. Such equipment is now becoming available, but it will be some time before it replaces that at present in use.

In 1963 the Williams filter was introduced. ${ }^{3}$ It could be used between the patient and the ventilator to protect the latter from contamination, but trapped moisture tended to increase the resistance to the flow of gas and to allow contaminating organisms to grow through. For this reason it was not very widely adopted. This filter was later modified by providing it with a heater to prevent condensation. ${ }^{4}$ Recently A. Holdcroft and her colleagues at Hammersmith have described the microbiological performance and successful use of another type of heated filter. 5 Yet another alternative is to siliconize the filter and make it water-repellent so that it does not need to be heated. Tests on this device are now reported by Drs. N. J. Mitchell and D. R. Gamble in this issue of the B.M.F. There are thus now available filters of at least two types which have been found satisfactory in practice with various sorts of ventilator. The use of such filters would largely eliminate the need to disinfect ventilators, leaving the tubing to be disinfected, preferably by heat, and the humidifier to be kept free of contamination by being run hot or filled with an antimicrobial solution. The Hammersmith paper was entitled, "Why Disinfect Ventilators?" and it would be useful if anaesthetists would ask themselves this question. If the need can be clearly defined they would save themselves and their microbiological colleagues much trouble and anxiety. If there should be a few situations in which disinfection is considered necessary, the formaldehyde method of M. K. Sykes 6 is comparatively easy to carry out, has been in routine use for nearly 10 years, and has recently been reevaluated and shown to be effective. ${ }^{7}$

To what extent are heated and siliconized filters proving successful and with what types of ventilators? The manufacturers are probably the people best able to collect such information, and they would be giving a valuable service to anaesthetists, and indeed to microbiologists, if they would do so and make their results available. An important question remains: How much infection occurring in patients on ventilators is due to the ventilator and how much to other causes? If the ventilator can be effectively exonerated by fitting it with filters the way is open for the matter to be studied epidemiologically by anaesthetists and microbiologists working together. This should prove to be of scientific interest and in the long run helpful to these patients.

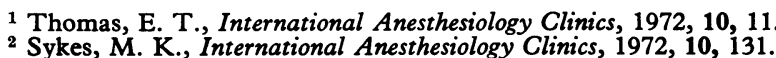

3 Bishop, C., Roper, W. A. G., and Williams, S. R., British fournal of Anaesthesia, 1963, 35, 32.

4 Pyle, P., Darlow, M., and Firman, J. E., 1969, Lancet, 1, 136.

5 Holdcroft, A., Lumley, J., and Gaya, H., 1973, Lancet, 1, 240.

- Sykes, M. K., British Medical fournal, 1964, 1, 561.

Benn, R. A. V., Dutton, A. A. C., and Tully, M., 1972, Anaesthesia, 27, 265 .

\section{Lymphocyte-depletion Hodgkin's Disease}

Even in the days before it was generally agreed that Hodgkin's disease was a true neoplasm it was observed that cases in which the lesions consisted largely of lymphocytes carried a good prognosis and those in which lymphocytes were few progressed rapidly despite treatment. H. Jackson and F. Parker, from Boston, Massachusetts, writing in 1944 divided the disease into three types: Hodgkin's paragranuloma, in which lymphocytes were the predominant cells; Hodgkin's granuloma, in which there were more ReedSternberg cells and fewer lymphocytes; and Hodgkin's sarcoma, with few lymphocytes and many reticulum cells and Reed-Sternberg cells. ${ }^{1}$ After following up cases of each type these authors concluded that Hodgkin's paragranuloma was a comparatively benign condition, Hodgkin's granuloma was usually fatal in a few years, and Hodgkin's sarcoma was rapidly fatal. ${ }^{2}$

Lately there has been a great increase in knowledge and understanding of the lymphocyte's role in immunity to 
disease and particularly to neoplastic disease. It is now recognized that in the most favourable type of Hodgkin's disease the neoplastic reticulum and Reed-Sternberg cells are strongly antigenic. They evoke a cell-bound antibody response in the form of many lymphocytes, whereas in the less favourable types of disease the antigenicity or the corresponding lymphocyte response is weaker.

In response to these changing ideas $R$. J. Lukes and his colleagues, also from Boston, Massachusetts, produced a modern nomenclature of Hodgkin's disease. It is based on clinical features and microscopical appearances of the lesions and has been correlated with the natural history of the disease. ${ }^{3-5}$ An extreme but uncommon variant of the disease is classified by them as lymphocyte-depletion Hodgkin's disease. R. S. Neiman and colleagues have recently found 12 cases of this variant in the records of Los Angeies County University of Southern California Medical Center from January 1960 to June 1972 and have added a thirteenth from the personal records of Lukes. 6 The patients were from 18 to 73 years of age, with a mean of 51 years. Ten of them were males. They usually presented with fever, night sweats, loss of weight, and profound weakness. In only three cases were large axillary or inguinal masses found, and in six cases there was no detectable lymph node enlargement. In only one case were large hilar nodes detected radiologically, and enlargement of the liver and spleen was usually slight. Almost all the patients were anaemic, often with severe lymphocytopenia, leukopenia, and thrombocytopenia. The serum level of alkaline phosphatase was raised in many, and some of these patients were jaundiced. In 11 of them the diagnosis of Hodgkin's disease was made during life. It was based on biopsy of peripheral lymph nodes in six, biopsy of retroperipheral lymph nodes in two, and study of bone marrow in three.

As would be expected, these patients soon died despite treatment. The median time of survival from the date of their presentation was 5.5 months. One patient, however, responded to combined chemotherapy (nitrogen mustard, vincristine, procarbazine, and prednisone) with a remission lasting eight months, but died 10 months after the onset of the disease. At necropsy there was a striking hypoplasia of the bone marrow with widespread foci of Hodgkin's tissue without lymphocytes. The spleen and liver were also involved. Some lymph nodes were affected in all cases, but in only three of them above the diaphragm.

Lymphocyte-depletion Hodgkin's disease, with its unusal clinical features and unique pathological findings, appears to be distinct, if rare. Only 12 cases were found in as many years in one of the largest and most important "referral centers" in America. The cause of the lymphocyte depletion is unknown. Nor is it known why the Hodgkin's disease in this condition is confined to the reticuloendothelial system. The authors suggest that the patients may have been suffering from a form of immune failure analogous to a graftversus-host reaction in experimental animals and that the neoplastic condition of Hodgkin's disease arose as a secondary phenomenon in these lymphocyte-depleted people.

1 Jackson, H., jun., and Parker, F., jun, New England fournal of Medicine, $1944,231,35$.

2 Jackson, J., jun., and Parker, F., jun., New England fournal of Medicine, $1944,231,639$

${ }^{3}$ Lukes, R. J., American fournal of Roentgenology, Radium Therapy and Nuclear Medicine, 1963, 90, 944.

4 Lukes, R. J., Butler, J. J., and Hicks, E. B., Cancer, 1966, 19, 317.

5 Lukes, R. J., Craver, L. F., Hall, T. C., Rappaport, H., and Ruben, P., Cancer Research, 1966, 26, 1311. - Nieman, R. S., Rosen, P. J., and Lukes, R. J., New England fournal of
Medicine, 1973, 288, 751.

\section{Economics of Varicose Veins}

Varicose veins present in many different shapes and sizes. They vary from the scarcely visible dilated vessels which mar the appearance of a young woman's leg to the mass of tortuous veins endured over many years or to extensive induration and ulceration of the lower calf. They constitute a major part of every surgical waiting list, and delay in treatment is usually inevitable owing to the numbers of patients or to the priority that the surgeon gives to other conditions.

Injection treatment was used for many years with uncertain results and was then largely superseded by stripping of the long or short saphenous veins. Subsequently W. G. Fegan $^{1}$ introduced a new concept of injection-compression sclerotherapy, which has gained wide acceptance, though opinions on its efficacy differ. This technique entails the injection of sclerosant into an isolated segment of virtually empty vein, followed by compression for six weeks to ensure obliteration of the injected vein. Because sclerotherapy can be undertaken on an outpatient basis, patients usually prefer it to surgical treatment. ${ }^{2}$ It is an economic help to them, for they can continue with normal activities while under treatment. Another advantage is that pressure on expensive bed space and theatre time is reduced. However, Fegan himself concedes that there is a place for surgical treatment, and each surgeon will make his own decision on the appropriate form of treatment for each individual case.

D. Piachaud and J. M. Weddell ${ }^{2}$ have attempted to assess the relative economics of sclerotherapy and surgical treatment. From a three-year trial they concluded that there was little difference in the efficacy of the two methods. On the basis of an average of $7 \cdot 3$ outpatient attendances for sclerotherapy, they assessed the cost as $£ 9.77$ per patient treated. With an average inpatient stay of 3.7 days they assessed the cost of surgical treatment as $£ 44 \cdot 22$ per patient treated. The mean loss of work due to injection treatment was found to be 6.4 days and was costed at $£ 29$ loss of earnings per patient, whereas surgical treatment involved a mean loss of 31.3 days' work, costed at $£ 118$. Whatever inaccuracies such estimates may contain, it is clear that the economics of sclerotherapy confer an advantage on the patient and conserve the resources of the Health Service. Since the 1966 figures for bed occupancy by patients undergoing treatment for varicose veins was 32.6 beds occupied daily per million of population in the U.K., ${ }^{3}$ and since this exceeded the provision needed for treatment of appendicitis, the scope for economy is substantial.

Even so, no one method of treatment is applicable to all cases of varicose veins, and surgery is often preferable when there is gross incompetence of either saphenous vein or when incompetent perforating veins are hidden by subcutaneous induration of the lower calf. In some cases a combination of the two methods is required, and sclerotherapy is employed to obliterate varices which remain after surgical treatment.

Although injection-compression sclerotherapy is gaining ground and is leading to more efficient use of valuable beds, the results obtained do not always measure up to some of the claims made for it. Results depend on attention to detail, and the injection of sclerosant into a half-filled vein followed by perfunctory bandaging for a week or two will not suffice. Sclerotherapy should be performed at a well-organized outpatient session and supervision continued until treatment is complete. Consequently, it is often easier to enter the patient's name on the surgical waiting list and leave the 